\title{
Multiple sporadic cerebral cavernous malformations
}

\section{Múltiplos cavernomas cerebrais esporádicos}

Rodrigo Alencar e Silva', Thadeu Alexandre Paulino de Souza², Thiago Cardoso Vale ${ }^{3}$

A32-year-old previously healthy man presented with headache that progressively worsened during the day. He denied any previous history of headache and trauma. There was no family history of neurological diseases. Examination revealed nuchal rigidity. Cranial computed tomography disclosed a left frontal hemorrhage. Brain magnetic resonance imaging revealed multiple cerebral cavernous malformations (CCM). The patient received conservative treatment. Cerebral cavernous malformations are commonly described in the familial form and are frequently asymptomatic. When symptoms do occur, seizures are the most common followed by focal deficits and headache ${ }^{1}$. Several mutations in CCM genes have already been identified in patients with sporadic disease ${ }^{2}$.

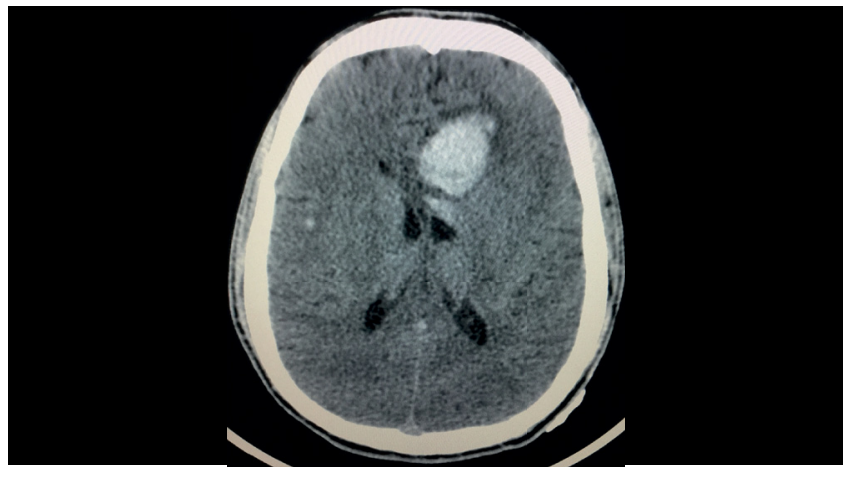

Figure 1. Axial cranial CT scan: an oval-shaped hyperdense lesion in the left frontal lobe with perilesional vasogenic edema and a small focus of blood in the contralateral frontal lobe.
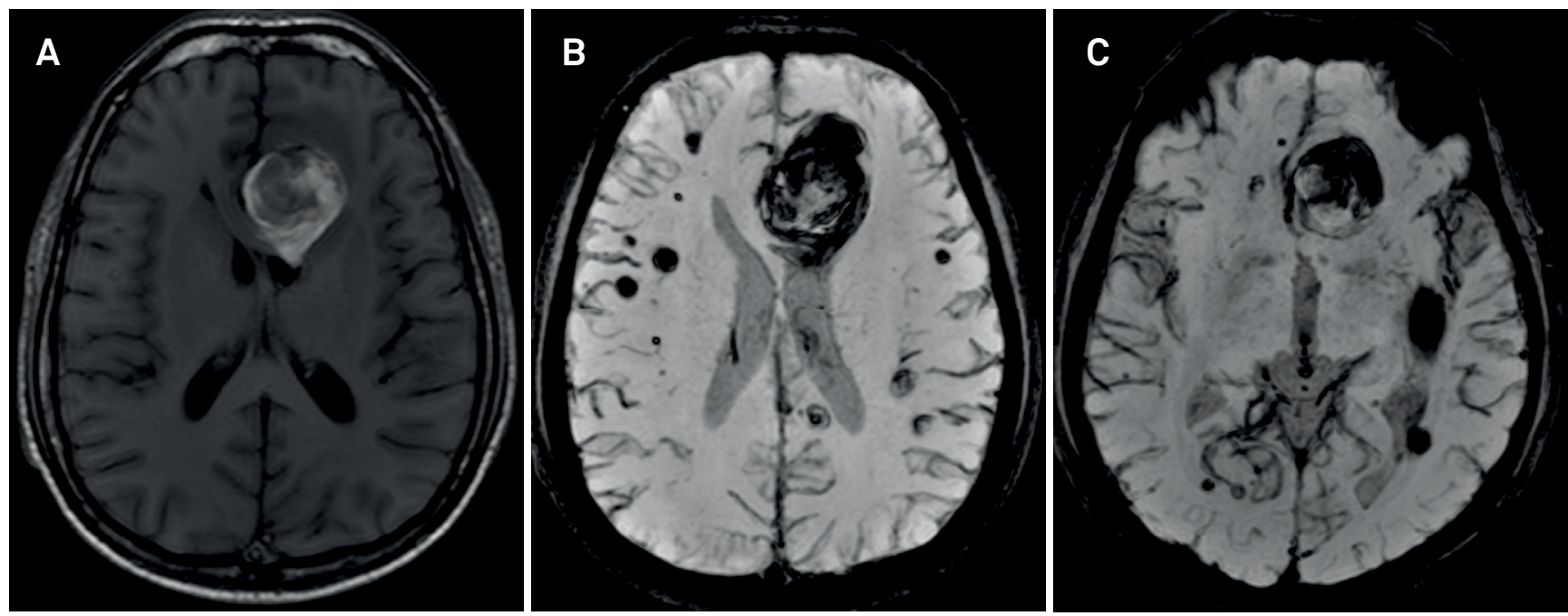

Figure 2. Brain MRI in axial T1 (A), Axial-susceptibility-weighted (B) and multiplanar reconstruction (C) showing an heterogeneous lesion with a hyperintense signal associated with perilesional vasogenic edema suggestive of acute hematoma. Additionally, there are multiple nodules with hypointense signal throughout the parenchyma and a subarachnoid hemorrhage in the left Sylvian fissure.

References

1. Chahine LM, Berg MJ. Clinical reasoning: cerebral cavernous malformations.

Neurology. 2009;73(9):e44-9.

https://doi.org/10.1212/WNL.0b013e3181b59a5b
2. Scimone C, Bramanti P, Alafaci C, Granata F, Piva F, Rinaldi C et al. Update on novel CCM gene mutations in patients with cerebral cavernous malformations. J Mol Neurosci. 2016;61(2):189-98. https://doi.org/10.1007/s12031-016-0863-z

\footnotetext{
${ }^{1}$ Hospital Monsenhor Walfredo Gurgel, Divisão de Neurologia, Natal RN, Brasil;

${ }^{2}$ Hospital Monsenhor Walfredo Gurgel, Divisão de Radiologia, Natal RN, Brasil;

${ }^{3}$ Universidade Federal de Juiz de Fora, Faculdade de Medicina, Hospital Universitário, Unidade de Distúrbios do Movimento, Serviço de Neurologia, Juiz de Fora MG, Brasil. Correspondence: Rodrigo Alencar e Silva; Avenida Campos Sales, 682 / Ap. 901B; 59020-300 Natal RN, Brasil; Email: alencar-rodrigo@hotmail.com Conflict of interest: There is no conflict of interest to declare.

Received 25 January 2017; Received in final form 28 August 2017; Accepted 05 September 2017.
} 